\title{
The Mechanical Properties of Moulded and Thermoformed Denture Resins
}

\author{
Sebastian Baloš ${ }^{1}$-Mladomir Milutinović1 - Michal Potran²-Jelena Vuletić2 - Tatjana Puškar² - Tomaž Pepelnjak3,* \\ ${ }^{1}$ University of Novi Sad, Faculty of Technical Sciences, Serbia \\ 2 University of Novi Sad, Medical Faculty, Serbia \\ 3 University of Ljubljana, Faculty of Mechanical Engineering, Slovenia
}

This study describes in detail the mechanical properties of polymethylmethacrylate (PMMA) denture base resins with regard to fabrication procedures, moulding and thermoforming. The investigation included eight specimens of each group of the materials, made separately for each experimental protocol (moulding and thermoforming). Analysis of the mechanical properties of the tested resins was comprised of tensile and 3-point bending strengths, elongation, fracture toughness and micro-hardness tests. Data obtained from the mechanical tests were statistically processed by using one-way analysis of variance (ANOVA) with Tukey's post-hoc test and with the significance level $\alpha=0.05$.

Triplex cold specimens showed the lowest bending strength, fracture toughness and micro-hardness as well the highest standard deviations. Biocryl $\mathrm{C}$ in a thermoformed condition exhibited higher tensile and bending strength in comparison to the same material but in the as-received condition (before thermoforming), while the results are opposite for fracture toughness and micro-hardness. Compared to Triplex hot, thermoformed Biocryl $\mathrm{C}$ had statistically non-significantly higher values for bending strength and micro-hardness, but significantly lower ones for fracture toughness and tensile strength. In contrast, the lowest dissipation of testing results in all mechanical tests was recorded for Biocryl C fabricated by a thermoforming process, meaning that this material has the highest predictability of the materials tested.

The mechanical properties of thermoformed PMMA materials are comparable to cold and hot polymerized PMMA materials. Standard deviations obtained for thermoformed PMMA material are lower than those obtained with cold and hot polymerized PMMA materials.

Keywords: polymethylmethacrylate denture resin, thermoforming, mechanical properties, denture base

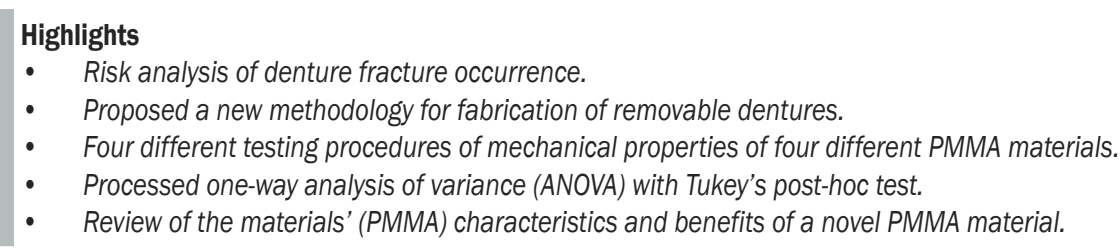

\section{INTRODUCTION}

Removable dentures are mobile dental (prostheses) that are used for replacing missing teeth in patients with partial or complete edentulism. Since 1940, the primary material for the fabrication of removable dentures has been polymethylmethacrylate [1] to [3]. Since then, much effort has been made in the improvement of characteristics of construction materials, affecting the composition of the materials and the addition of external supplements to increase their resilience [4]. The most commonly used method of strengthening polymethyl-methacrylate (PMMA) is impregnation with rubber (butadiene styrene) and the addition of various types of fibres [5]. Further improvement of mechanical properties of PMMA can also be conducted via microwave irradiation, as well as the addition of nanoparticles [6] to [8]. Better utilization of the materials' potential requires additional examination by the scientific community, because manufacturers are not required to state the full specification of the product, unless the ingredients of the material that have proven to be potentially harmful. Knowledge about each material and of its characteristics is necessary in order to choose the most suitable material for a given clinical situation.

According to the Hergravesa [9], the fact that $63 \%$ of dentures fracture occurs in the first three years of their use remains a problem in current denture applications [10]. Denture fracture usually appears in the midline of the palate (Fig. 1), due to the cyclic shifting between flexion and extension forces that occur during mastication. This was confirmed by the study of Khasawneh and Arab [11], which reported that $61 \%$ of fractures occur in the middle of the palate, which was further verified by in vitro studies by Prombonas and Vlissidis [12].

It has been stated that in the case of a mandibular complete denture, the midline stress field is planar, consisting of low intensity compressive forces and low shear stress. At the same time, the corresponding stress field of the maxillary complete denture is characterized by high tensile stresses and high shear stress. This is of particular importance when 
fabricating denture bases (Fig. 2) from brittle materials, such as PMMA, which exhibit significantly higher strength in compression than in tension [12].

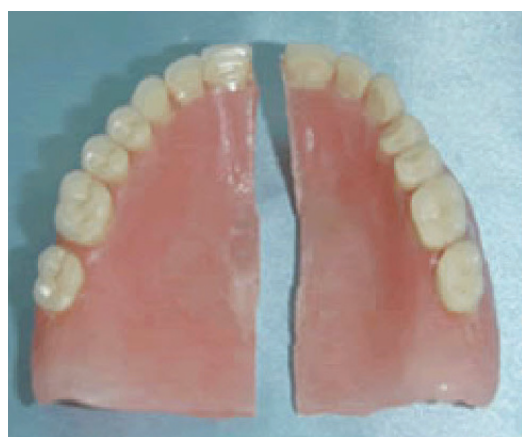

Fig. 1. The midline fracture of complete denture base

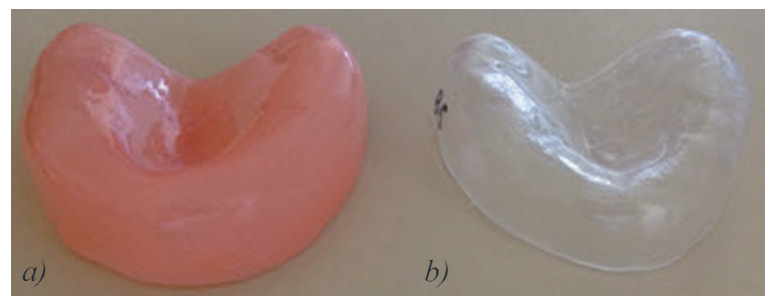

Fig. 2. Models of the denture base fabricated by a) moulding (PMMA - Triplex hot), and b) thermoforming (PMMA - Biocryl C)

This acknowledgement is often discarded in clinical practice, and the selection of a resin material is usually based on its bending strength. Because fracture lines are formed at the sites of internal or external micro-cracks, the tendency to form and propagate initial cracks i.e. fracture toughness, provides additional information for the proper selection of the denture base material. Micro-cracks within the material occur because of residual stresses that are induced during material processing, as well as a result of improper material handling, poor process control and thermal shrinkage [13]. High fracture toughness and crack resistance are prerequisites for minimizing the risk of denture failure due to a fracture. This is why clinical behaviour and the service life of dentures base might significantly differ from its mechanical potential and data given in the literature.

Conventional procedures for the construction of removable dentures include hot- and cold-curing acrylic resins. Because the conversion of monomers into long chains of polymers does not completely occur during the polymerization process, uneven polymerization can result in poor mechanical properties and reduced biocompatibility. Via the process of diffusion, residual monomers can be gradually released into the oral cavity, which can reduce the material's properties and possibly have a negative impact on health of the oral mucosa. The most common adverse effects are irritation of the oral mucosa and allergic reactions [14] and [15]. Consequently, the development of new materials is mainly focused on reducing the residual monomer content, while improving the ease of handling of the material. In addition, depending on the polymerization process, it is necessary to further standardize the procedures for making removable dentures, so that discrepancies in the material itself are reduced to minimum, which can lead to dentures of high quality.

Due to a complex interaction of various biological and mechanical influences in the oral cavity, predicting the behaviour of the material can be enhanced by correlation of its mechanical properties [16]. Correlation data can be used for detailed examination of resin capabilities as well as to reduce the testing time and cost for each particular resin. In relation to this, the aim of this study was to compare the mechanical properties of acrylic resins depending on the polymerization process, using five different mechanical properties (bending and ultimate tensile strength, elongation, fracture toughness and microhardness). A thermoforming material currently not yet used for dentures was selected for comparison with the conventional systems (hot- and cold-curing PMMA). According to the manufacturer, it does not contain residual monomers, and the polymerization process is conducted under strictly controlled conditions [17]. An additional objective was to compare the characteristics of the analysed material before and after the processing by the thermoforming. The obtained results were statistically processed, compared and analysed from different perspectives.

\section{MATERIALS AND METHODS}

The materials investigated in this study are shown in Table 1. The investigation included eight specimens of each group of the materials, made separately for each experimental protocol.

Materials were treated according to the manufacturers' instructions; a total of 128 specimens were used in this study. All the specimens were kept in distilled water for 7 days before testing, at a constant temperature of $37^{\circ} \mathrm{C}$.

Fabrication of the specimens included the production of wax patterns of an adequate shape that were further invested in gypsum mould. Polymerization of the cold-curing specimens was conducted in a pressure device (Ivomat, Ivoclar Vivadent, Lichtenstain) at $40{ }^{\circ} \mathrm{C}$ for 15 minutes under 
0.4 MPa pressure. Hot curing specimens were pressed at $7 \mathrm{MPa}$ (Reco Hydromatic press, Germany) after which polymerization was conducted at $100{ }^{\circ} \mathrm{C}$ for 45 minutes. Specimens of thermoplastic foil were made by cutting the specimens from the foil with a laboratory handpiece (K5plus, Kavo, Germany) before and after pressure moulding. The foil was pressure moulded on previously constructed gypsum pedestal, at $0.3 \mathrm{MPa}$ in a pressure-moulding device (Ministar $\mathrm{S}$, Scheu Dental, Germany). Specimens were further pre-polished (Abraso-soft acrylic, Bredent, Germany) and additionally polished (High lustre buff acrylic, Bredent, Germany) at $3000 \mathrm{rpm}$.

Testing procedures for measuring tensile and flexural strength were performed in accordance with ASTM D638 [18] and ISO 20795-1:2013 standards [19]. The tensile strength was determined on a universal testing machine (Model 1122, Instron, USA) with a crosshead speed of $10 \mathrm{~mm} / \mathrm{min}$ and the following equation:

$$
R_{m}=F_{m} / S_{o}
$$

where $R_{m}$ is the tensile strength [MPa], $F_{m}$ is the maximum force $[\mathrm{N}]$ and $S_{o}$ is a cross section $\left(\mathrm{mm}^{2}\right)$. The specimens for the tension test were designed following the ASTM D638 standard (type IV specimen). During loading of the specimen, a force vs. elongation diagram was automatically recorded by the machine plotter. The elongation was calculated as:

$$
A=\frac{\left(L-L_{o}\right)}{L_{o}} \cdot 100[\%]
$$

where $L$ is the fracture length and $L_{\mathrm{o}}$ is the gauge length $(25 \mathrm{~mm})$.

Determination of three-point bending strength was done by testing of eight specimens per sample group. Specimen dimensions were: $L \times B \times H=$
$(50 \pm 0.2) \times(6 \pm 0.1) \times(3 \pm 0.1) \mathrm{mm}$. This was done on a universal testing machine (AT-L-118B, Toyoseiki, Japan) with a crosshead speed of $1 \mathrm{~mm} / \mathrm{min}$ and the distance between the supports of $40 \mathrm{~mm}$. Bending strength was calculated using Eq. (3):

$$
\sigma=\frac{3 F_{\max } \cdot L}{2 B \cdot H^{2}}
$$

where $\sigma$ is the bending strength $[\mathrm{MPa}], F_{\max }$ is the maximum load [N], $L$ is the distance between supports [mm], $B$ is the width of the specimen [mm] and $H$ is the height of the specimen $(L=50 \pm 0.2 \mathrm{~mm}$, $B=6 \pm 0.1 \mathrm{~mm} H=3 \pm 0.1 \mathrm{~mm}$ ). Fracture toughness was tested using a conventional tensile testing machine AT-L-118B), equipped with a 4-point bending device with distance between the supports of $20 / 40 \mathrm{~mm}$. Crosshead speed was kept constant at $1 \mathrm{~mm} / \mathrm{min}$. The single edge V-notch beam (SEVNB) method was used according to ASTM D5045, [20] with specimen dimensions of $(45 \pm 0.2) \times(4 \pm 0.1) \times(3 \pm 0.1) \mathrm{mm}$ and a notch cut at the longitudinal centre. The preliminary U-notch was machined manually using a precision drill/grinder (FBS12; Proxxon, Germany) with a stroke of 3000 to $15000 \mathrm{~min}^{-1}$ fitted with a $\varnothing 20 \times 0.8$ $\mathrm{mm} \mathrm{SiC} \mathrm{disk.} \mathrm{The} \mathrm{final} \mathrm{V}$-notch was cut manually into the centre of the U-notch, acting as an initial crack. In order to achieve this, a commercial razor was used (Platinum; Gillette, Boston, Mass). This method has been described previously for ceramic and brittle polymer materials, [21] to [23]. The V-notch depth was measured with a light microscope (Orthoplan; Leitz/ Leica, Germany). Fracture toughness was calculated in accordance with Eq. (4):

$$
K_{I C}=\frac{F}{B \sqrt{W}} \frac{S_{1}-S_{2}}{W} \frac{3 \sqrt{\alpha}}{2(1-\alpha)^{1.5}} Y^{*}
$$

where $F$ is the maximum force [N], $S_{1}$ and $S_{2}$ are the distances between the supports $[\mathrm{mm}], \alpha$ is the

Table 1. Materials used in the study

\begin{tabular}{lllll}
\hline Group & Index & Manufacturer & Composition* & Curing method \\
\hline Triplex Cold & C & $\begin{array}{l}\text { Ivoclar Vivadent, } \\
\text { Schaan, Liechtenstein }\end{array}$ & $\begin{array}{l}\text { Powder: PMMA, dibenzoyl peroxide, pigments } \\
\text { Liquid: MMA, ethylene dimethacrylate, stabilizer }\end{array}$ & $\begin{array}{l}13 \mathrm{~g}: 10 \mathrm{mIM} \text {; Chemical polymerization on } \\
40^{\circ} \mathrm{C}, \text { pressure } 0.4 \mathrm{MPa}-15 \mathrm{~min}\end{array}$ \\
\hline $\begin{array}{l}\text { Triplex Hot } \\
\text { H }\end{array}$ & $\begin{array}{l}\text { Ivoclar Vivadent, } \\
\text { Schaan, Liechtenstein }\end{array}$ & $\begin{array}{l}\text { Powder: PMMA, dibenzoyl peroxide, pigments } \\
\text { Liquid: MMA, ethylene dimethacrylate }\end{array}$ & $\begin{array}{l}23 \mathrm{~g}: 10 \mathrm{ml} \\
\text { Heat polymerization on } 100^{\circ} \mathrm{C}-45 \mathrm{~min}\end{array}$ \\
\hline $\begin{array}{l}\text { Biocryl C } \\
\text { (before**) }\end{array}$ & AR & $\begin{array}{l}\text { Scheu Dental, } \\
\text { Iserlohn, Germany }\end{array}$ & polymethylmethacrylat & Prepolymerized by the manufacturer \\
\hline $\begin{array}{l}\text { Biocryl C } \\
(\text { after* }\end{array}$ & TF & $\begin{array}{l}\text { Scheu Dental, } \\
\text { Iserlohn, Germany }\end{array}$ & polymethylmethacrylat & $\begin{array}{l}\text { Prepolymerized by the manufacturer, heating } 90 \\
\text { s moulding pressure } 0.3 \mathrm{MPa}\end{array}$ \\
\hline
\end{tabular}

* composition according to the data sheet supplied by the manufacturer

** before and after thermoforming 
geometrical factor having the value of $a / W, a$ is the overall notch depth [mm], $B$ is the sample thickness [mm], $W$ is sample width [mm] and $Y^{*}$ is the specimen geometric function or a geometric factor, which is dimensionless and given as follows:

$$
\begin{aligned}
Y^{*} & =1.9887-1.32 \alpha- \\
& -\left(3.49-0.68 \alpha+1.35 \alpha^{2}\right)^{\alpha(1-\alpha)(1+\alpha)-2} .
\end{aligned}
$$

Micro-hardness was measured using a Vickers micro-hardness tester (HVS-1000; Huayin, China) and the following parameters: $300 \mathrm{~g}$ load and $15 \mathrm{~s}$ dwell time, according to Balos et al. [24]. Ten indentations were made per each specimen with the following dimensions: diameter $20 \mathrm{~mm}$, thickness $3 \mathrm{~mm}$. Microhardness was calculated using Eq. (6):

$$
H V=1.8544 \frac{F}{d^{2}},
$$

where $H V$ is the Vickers hardness number, $F$ is the load [kg] and $d$ is the average between indentation diagonals $[\mathrm{mm}]$.

The mechanical properties were analysed using a one-way analysis of variance (ANOVA) with Tukey's post-hoc test, with the significance level $\alpha=0.05$. Statistical analysis was performed with Minitab 16 (Minitab Inc., State College, USA) software.

\section{RESULTS}

The results of mechanical tests performed on selected materials are shown in Figs. 3 to 9, as well as Tables 2 to 6 . The typical stress vs. elongation curves are shown in Fig. 3. The highest tensile strength was obtained in specimen group $\mathrm{H}$, followed by $\mathrm{C}, \mathrm{TH}$, and AR (Fig. 4 and Table 2). It can be noted that there is a statistical difference between specimen group $\mathrm{C}$ and $\mathrm{H}$ on one side and $\mathrm{AR}$ and $\mathrm{TF}$ on the other side. Standard deviations are smaller in sample groups AR and TF.

In Fig. 5, fractured tensile specimens of groups $\mathrm{TF}$ and $\mathrm{C}$ are shown. It can be seen that fractures occur randomly in the $\mathrm{TF}$ group, while in the $\mathrm{C}$ specimen group, fractures occur predominantly near the specimens' shoulder. The results of ultimate elongation are shown in Table 3 and Fig. 6. The specimens belonging to the $\mathrm{H}$ and $\mathrm{TF}$ groups showed similar stretching behaviour (average value of this parameter is almost identical), while a significantly lower value was obtained with specimens from group C.

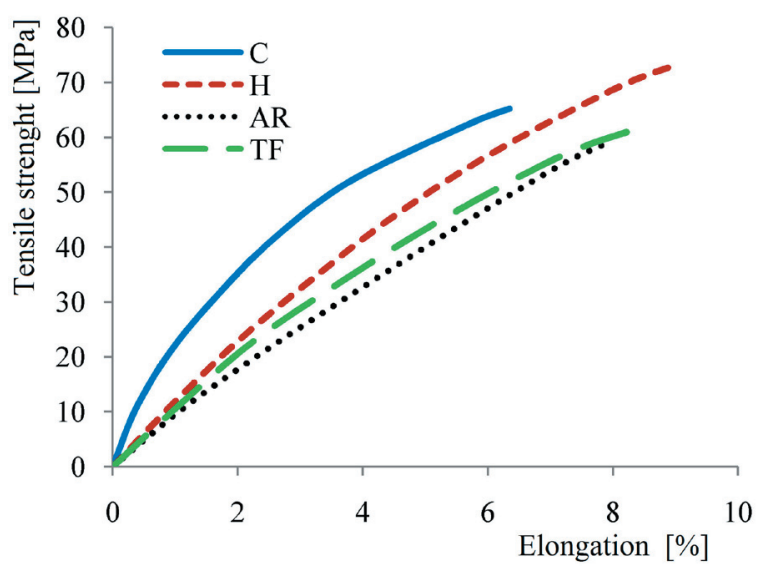

Fig. 3. Typical tensile stress-elongation curves obtained in the tensile test

\begin{tabular}{|c|c|c|c|}
\hline Group & Mean $R_{m}[\mathrm{MPa}]$ & Standard deviation & Grouping* \\
\hline $\mathrm{C}$ & 67.94 & 6.06 & $A$ \\
\hline $\mathrm{H}$ & 73.46 & 4.53 & A \\
\hline$A R$ & 59.46 & 3.90 & B \\
\hline TF & 60.58 & 3.69 & $B$ \\
\hline Source & SS & MS & $\mathrm{P}$ \\
\hline Factor & 1299.8 & 433.3 & 0.000 \\
\hline Error & 775.2 & 21.5 & \\
\hline Total & 2075.1 & & \\
\hline
\end{tabular}

Table 2. Mean tensile strengths, standard deviations and corresponding statistical parameters

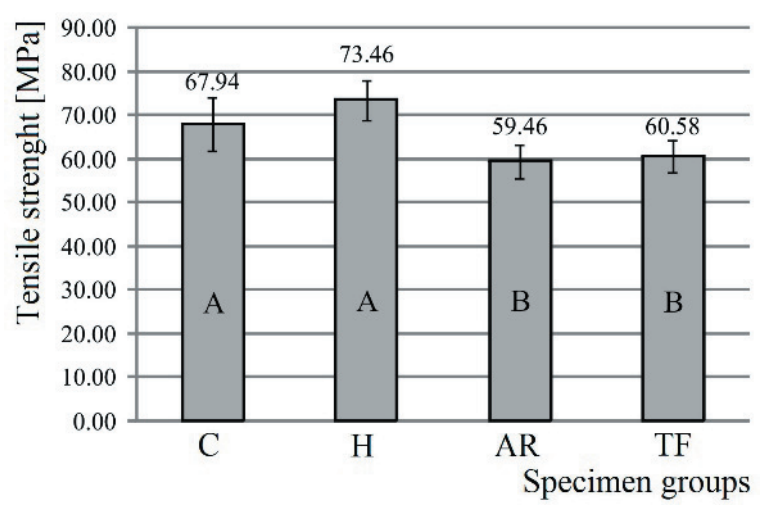

Fig. 4. Graphic of tensile strength of tested materials with standard deviations

Table 4 and Fig. 7 show the results of a 3-point bending test, i.e. flexural strength of tested materials. It can be seen that the highest 3-point bending strength is obtained with TF specimen group, while the lowest for C group. Standard deviation of TF group is the 
smallest of all tested groups. However, the statistical analysis proved that the differences between tested groups are not significant.
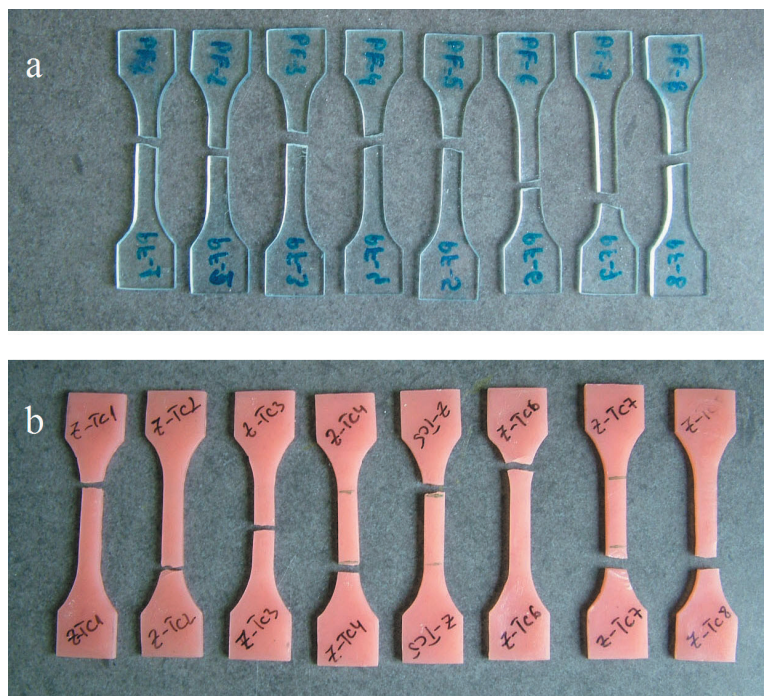

Fig. 5. The location of fractures in tensile testing; a) Biocryl C (after thermoforming), b) Triplex cold

Table 3. Mean elongations, standard deviations and corresponding statistical parameters

\begin{tabular}{cccc}
\hline Group & Mean $A$ [\%] & Standard Deviation & Grouping $^{*}$ \\
\hline $\mathrm{C}$ & 6.44 & 0.74 & $\mathrm{~A}$ \\
\hline $\mathrm{H}$ & 8.47 & 0.80 & $\mathrm{~B}$ \\
\hline $\mathrm{AR}$ & 7.88 & 0.30 & $\mathrm{~B}$ \\
\hline $\mathrm{TF}$ & 8.43 & 0.57 & $\mathrm{~B}$ \\
\hline
\end{tabular}

\begin{tabular}{lccccc}
\hline Source & DF & SS & MS & F & P \\
\hline Factor & 3 & 21.668 & 7.223 & 17.86 & 0.000 \\
\hline Error & 36 & 11.326 & 0.404 & & \\
\hline Total & 39 & 32.994 & & & \\
\hline
\end{tabular}

*different letters indicate statistically significant difference between the results.

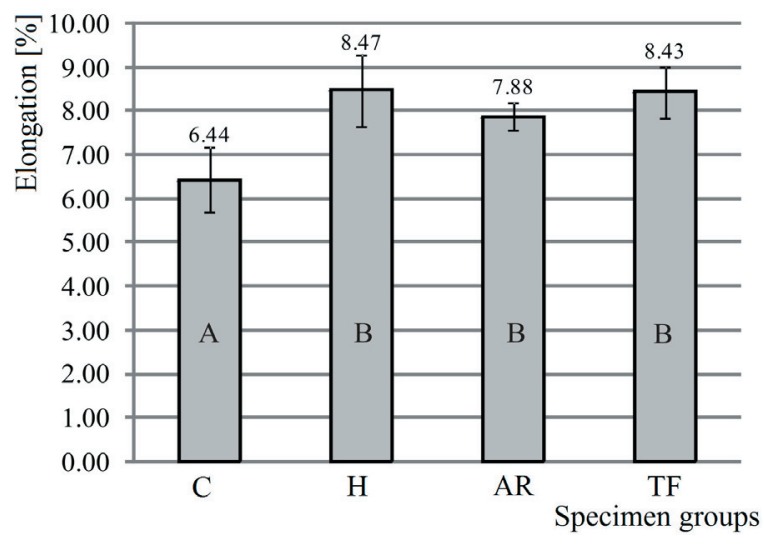

Fig. 6. Elongation of tested materials with standard deviations
Table 4. Mean 3-point bending strengths, standard deviations and corresponding statistical parameters

\begin{tabular}{|c|c|c|c|c|c|}
\hline Group & \multicolumn{2}{|c|}{ Mean $\sigma[\mathrm{MPa}]$} & \multicolumn{2}{|c|}{ Standard Deviation } & Grouping* \\
\hline $\mathrm{C}$ & \multicolumn{2}{|c|}{100.23} & \multicolumn{2}{|c|}{10.05} & $\mathrm{~A}$ \\
\hline $\mathrm{H}$ & \multicolumn{2}{|c|}{103.27} & \multicolumn{2}{|c|}{9.00} & $\mathrm{~A}$ \\
\hline $\mathrm{AR}$ & \multicolumn{2}{|c|}{102.23} & \multicolumn{2}{|c|}{8.33} & $\mathrm{~A}$ \\
\hline TF & \multicolumn{2}{|c|}{104.88} & \multicolumn{2}{|c|}{4.69} & $\mathrm{~A}$ \\
\hline Source & $\mathrm{DF}$ & SS & MS & $\mathrm{F}$ & $\mathrm{P}$ \\
\hline Factor & 3 & 113.8 & 37.9 & 0.56 & 0.648 \\
\hline Error & 36 & 2460.0 & 68.3 & & \\
\hline Total & 39 & 2573.9 & & & \\
\hline
\end{tabular}

*different letters indicate statistically significant difference between the results.

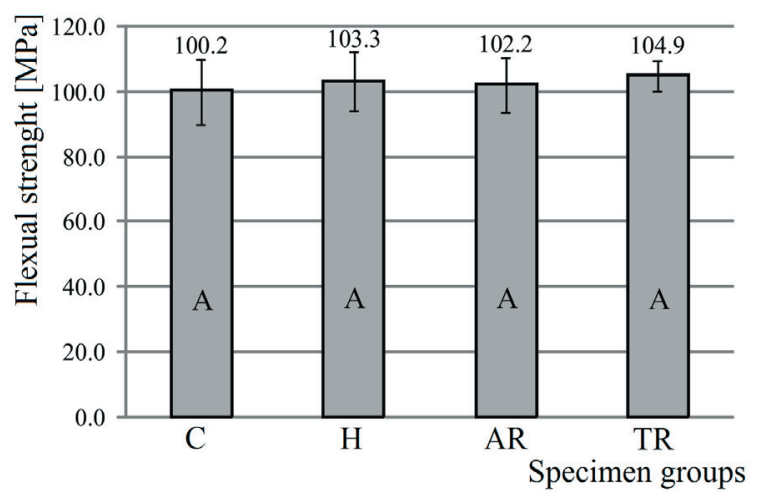

Fig. 7. Graphic of 3-point bending strengths of tested materials with standard deviations

The fracture toughness results are shown in Table 5 and Fig. 8. The difference between the specimen group with the highest and the lowest fracture toughness ( $\mathrm{C}$ and $\mathrm{H}$ group) is significant. Such results are obtained in spite of the lowest standard deviations. Furthermore, it can be noted that the TF specimen group has lower fracture toughness than the AR specimen group.

Table 5. Mean fracture toughnesses, standard deviations and corresponding statistical parameters

\begin{tabular}{|c|c|c|c|c|c|}
\hline Group & \multicolumn{2}{|c|}{ Mean $K_{I C}\left[\mathrm{MPam}^{1 / 2}\right]$} & \multicolumn{2}{|c|}{ Standard Deviation } & Grouping* \\
\hline $\mathrm{C}$ & \multicolumn{2}{|c|}{1.230} & \multicolumn{2}{|c|}{0.06} & $\mathrm{~A}$ \\
\hline $\mathrm{H}$ & \multicolumn{2}{|c|}{1.803} & \multicolumn{2}{|c|}{0.10} & B \\
\hline$A R$ & \multicolumn{2}{|c|}{1.403} & \multicolumn{2}{|c|}{0.09} & C \\
\hline TF & \multicolumn{2}{|c|}{1.236} & \multicolumn{2}{|c|}{0.08} & A \\
\hline Source & $\mathrm{DF}$ & SS & MS & $\mathrm{F}$ & $P$ \\
\hline Factor & 3 & 2.17068 & 0.72356 & 0.72356 & 0.000 \\
\hline Error & 36 & 0.25506 & 0.00709 & 0.00709 & \\
\hline Total & 39 & 2.43574 & & & \\
\hline
\end{tabular}

*different letters indicate statistically significant difference between the results. 


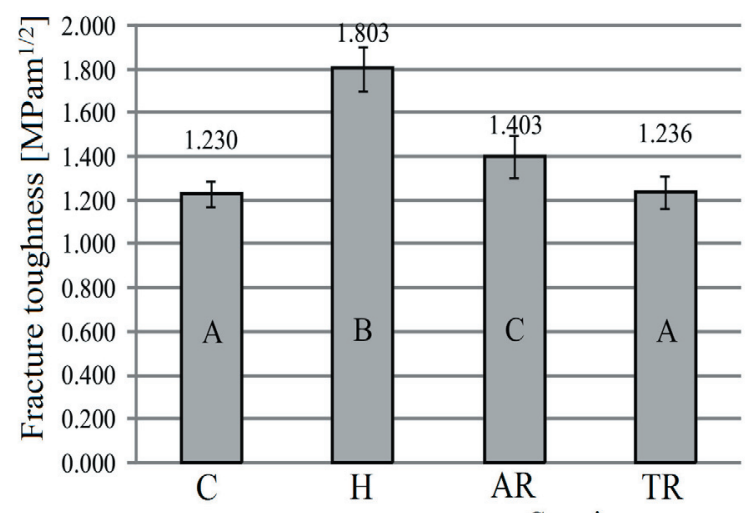

Fig. 8. Fracture toughness of tested materials with standard deviations

In terms of micro-hardness, the highest results were obtained for AR specimen group (Table 6 and Fig. 9). The results demonstrate that the $\mathrm{H}, \mathrm{AR}$, and TF specimen groups have a significantly higher microhardness compared to the $\mathrm{C}$ group. Furthermore, it can be noted that the standard deviation in the $\mathrm{C}$ specimen group is higher than in AR and TF group.

Table 6. Mean micro-hardnesses HVO.3, standard deviations and corresponding statistical parameters

\begin{tabular}{|c|c|c|c|c|c|}
\hline Group & \multicolumn{2}{|c|}{ Mean $H V 0.3$} & \multicolumn{2}{|c|}{ Standard Deviation } & Grouping* \\
\hline$C$ & \multicolumn{2}{|c|}{19.66} & \multicolumn{2}{|c|}{1.22} & $A$ \\
\hline $\mathrm{H}$ & \multicolumn{2}{|c|}{21.65} & \multicolumn{2}{|c|}{0.63} & $\mathrm{~B}$ \\
\hline $\mathrm{AR}$ & \multicolumn{2}{|c|}{22.43} & \multicolumn{2}{|c|}{0.35} & $\mathrm{~B}$ \\
\hline TF & \multicolumn{2}{|c|}{21.96} & \multicolumn{2}{|c|}{0.31} & $B$ \\
\hline Source & DF & SS & MS & $\mathrm{F}$ & $\mathrm{P}$ \\
\hline Factor & 3 & 44.62 & 14.87 & 28.22 & 0.000 \\
\hline Error & 36 & 18.97 & 0.527 & & \\
\hline Total & 39 & 63.59 & & & \\
\hline
\end{tabular}

*different letters indicate statistically significant difference between the results.

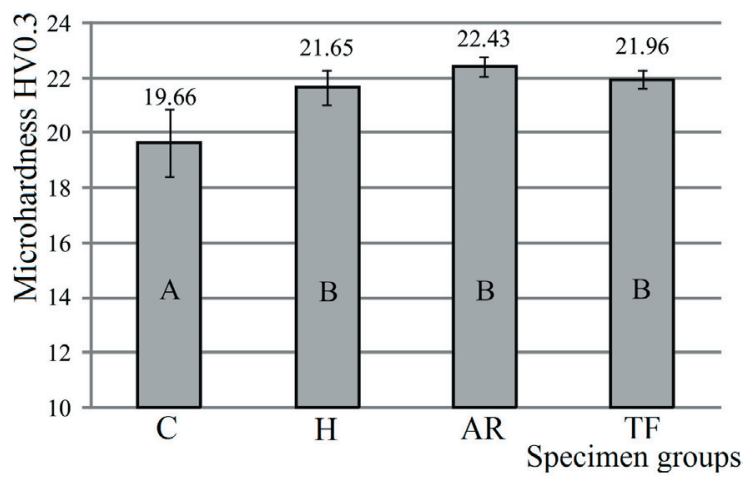

Fig. 9. Micro-hardness of tested materials with standard deviations

\section{DISCUSSION}

The aim of this paper was to compare conventional hot- and cold-curing ( $\mathrm{H}$ and $\mathrm{C}$ ) denture base materials and a novel PMMA material in as-received factory polymerized and thermoformed states (AR and TF). A full mechanical testing characterization was performed in order to evaluate material performance from different aspects.

The C specimen group, obtained in cold conditions (auto-polymerized PMMA), had the lowest elongation, bending strength, fracture toughness and micro-hardness. Such results are expected, due to a limited preparation time before the polymer becomes sufficiently viscous to prevent any further mixing [6] and [7]. Furthermore, standard deviations in the $\mathrm{C}$ specimen group are the highest of all the tested materials, the only exception being fracture toughness. Compared to $\mathrm{C}$, the mechanical properties of the $\mathrm{H}$ specimen group are higher, which was expected due to a prolonged mixing and preparation, as well as additional compression and water heat after treatment aimed at decreasing monomer content [25]. Fracture location that occurs predominantly in one specific area (near specimen shoulder) indicates that the $\mathrm{C}$ specimen group may suffer from structural inconsistencies.

The tensile and bending strengths of the TF specimen group are slightly higher compared to the AR specimen group, with lower standard deviations. In contrast, the AR group has a higher micro-hardness compared to the TF group, but this advantage is also statistically insignificant. Only the fracture toughness of the AR is significantly higher than that of the TF group. Nevertheless, the TF specimen group's fracture toughness is significantly lower than that of both the $\mathrm{H}$ and AR groups and statistically equal to the $\mathrm{C}$ group. That means that the TF specimen group is more sensitive to load when a crack is present on the specimen surface. Although dentures theoretically initially do not have surface cracks, an array of defects may be present in the materials structure: porosity, inhomogeneous structure, surface flaws, etc. [13]. Furthermore, standard deviations in fracture toughness test may not be considered to be as the most representative, because the initial crack was made manually, i.e. manual initial crack preparation might induce a certain level of inaccuracy. However, based on obtained results, it can be said that the TF specimen group requires a more careful polishing compared to the $\mathrm{H}$ tested group.

The standard deviations in TF specimen group have relatively low standard deviations, which 
might be achieved due to the factory synthesis and polymerization process. Such material preparation might be more accurate than the preparation in dental laboratory, where several operations are dependent on the technicians' skill.

The moderate increase in tensile and bending strengths, as well as the elongation of the TF versus AR specimen groups, although statistically nonsignificant, may be the result of a partial orientation of polymer chains during thermoforming. However, in specimens in which a strictly local deformation is induced (micro-hardness and fracture toughness testing) partially oriented polymer chains may offer a lower resistance due to relatively weak secondary bonds between them. The crack may propagate between the partially oriented chains more efficiently (TF group) than through the material with a more random polymer chain orientation (AR group). Testing results were also confirmed the fact that for brittle polymer materials bending strength is greater than tensile strength. In the literature, there are a few explanations for this phenomenon [26] to [28]. Another possible interpretation for this difference might be found in the structure of polymer material, i.e. in the bonds between the individual monomer components of the long chains such as carbon-carbon sigma bonds. In addition, monomer components have some dipoles perpendicular to the axis of the polymeric chain [29]. Because of this dipole, the parallel chains have some repulsion between them, which contributes to the bending strength of the polymer on the macro level. The bending interaction must overcome the repulsion as well as break the inter-monomer bonds in order to break the polymer material, whereas a tensile interaction must only break the inter-monomer bonds in enough places in each chain so as to cause macroscale failure.

When addressing its use in dental practice, it can be concluded that the novel PMMA material used in this study (AR, TH) showed satisfactory results compared to the conventional systems $(\mathrm{H}, \mathrm{C})$. The key benefits of the material, i.e. structural consistency and ease of handling, offer benefits for clinicians when constructing dental appliances. Further research will be focused on the clinical assessment of material properties, regarding their resilience, durability and comfort of wear for the patients.

\section{CONCLUSIONS}

In accordance with the obtained results, some conclusions can be drawn:
- Thermoformed PMMA materials mechanical properties are comparable to cold and hot polymerized PMMA materials. The tensile strength of thermoformed PMMA material is significantly lower than those of cold and hot PMMA materials. Furthermore, fracture toughness is lower for thermoformed than that of hot polymerized PMMA.

- Standard deviations obtained for thermoformed PMMA material are lower than those obtained with cold and hot polymerized PMMA materials. That means that the repeatability of the results and the consistency of mechanical properties is higher for the thermoformed PMMA.

- The main reason for the relatively high consistency of the obtained mechanical properties in thermoformed specimens may be attributed to industrial polymerization process, which might be more accurate than the preparation in the dental laboratory.

\section{ACKNOWLEDGEMENT}

The results of the investigation presented in this paper are part of the research realized in the framework of the project "Research and development of modeling methods and approaches in manufacturing of dental recoveries with the application of modern technologies and computer aided systems"-TR 035020, financed by the Ministry of Science and Technological Development of the Republic of Serbia.

The authors also thank the CEEPUS program for making them possible to be mobile within the network CII-HR-0108.

\section{REFERENCES}

[1] Jagger, D.C., Harrison, A., Jandt, K.D. (1999). The reinforcements of dentures-review. Journal of Oral Rehabilitation, vol. 26, no. 3, p. 185-194, Dol:10.1046/ j.1365-2842.1999.00375.x.

[2] Bettencourt, A.F., Neves, C.B., de Almeida, M.S., Pinheiro, L.M., Oliveira, S.A., Lopes, L.P., Castro, M.F. (2010). Biodegradation of acrylic based resins: A review. Dental Materials, vol. 26, no. 5, p. 171-180, D0l:10.1016/j.dental.2010.01.006.

[3] Krunic, N., Kostic, M., Andelkovic, M. (2007). Acrylic resinsstill irreplacable material in prosthetic dentistry. Acta Stomatologica Naissi, vol. 23, no. 56, p. 747-752. (in Serbian)

[4] Asar, N.V., Albayrak, H., Korkmaz, T., Turkyilmaz, I. (2013). Influence of various metal oxides on mechanical and physical properties of heat-cured polymethyl methacrylate denture base resins. Journal of Advanced Prosthodontics, vol. 5, no. 3, p. 241-247, DOI:10.4047/Jap.2013.5.3.241. 
[5] Vallittu, P.K. (1996). A review of fiber reinforced denture base resins. Journal of Prosthodontics, vol. 5, no. 4, p. 270-276, D0I:10.1111/j.1532-849X.1996.tb00511.x.

[6] Balos, S., Balos, T., Sidjanin, L., Markovic, D., Pilic, B., Pavlicevic, J. (2011). Study of PMMA Biopolymer Properties Treated by Microwave Energy. Materiale Plastice, vol. 48, no. 2, p. 127-131.

[7] Balos, S., Balos, T., Sidjanin, L., Markovic, D., Pilic, B., Pavlicevic, J. (2009). Frexural and impact Strength of Microwave Treated Autopolymerized Poly (MethylMethacrylate). Materiale Plastice, vol 46, no. 3, p. 261-265.

[8] Balos, S., Pilic, B., Markovic, D., Pavlicevic, J., Luzanin, 0. (2014). Poly(methyl-methacrylate) nanocomposites with low silica addition. Journal of Prosthetic Dentistry, vol. 111, no. 4, p. 327-334, D0I:10.1016/j.prosdent.2013.06.021.

[9] Hargreaves, A.S. (1969). The prevalence of fractured dentures. A survey. British Dental Journal, vol. 126, no. 10, p. 451-455.

[10] Curtis R.V., Watson, T.F. (eds.) (2009). Dental biomaterials Imaging, Testing and Modeling, Wookhead Publishing, Cambridge.

[11] Khasawneh, S.F., Arab, J.M. (2003). A clinical study of complete denture fractures at four military hospitals in Jordan. Jordanian Royal Medical Services, vol. 10, no. 2, p. 27-31.

[12] Prombonas, A.E., Vlissidis, D.S. (2006). Comparison of the midline stress fields in maxillary and mandibular complete dentures: A pilot study. Journal of Prosthetic Dentistry, vol. 95, no. 1, p. 63-70, D0l:10.1016/j.prosdent.2005.11.009.

[13] Anusavice, K. J., Shen, C., Rawls, H. R. (2013). Phillips' Science of Dental Materials, 12th ed., Elsevier/Saunders, St. Louis.

[14] Austin, A.T, Basker, R.M. (1982). Residual monomer levels in denture bases. The effect of varying short curing cycles. British Dental Journal, vol. 53, no. 12, p. 424-426, Dol:10.1038/ sj.bdj.4804962.

[15] Autian, J. (1975). Structure-toxicity relationship of acrylic monomers. Environmental Health Perspectives, vol. 11, p. 141-152, D0I:10.1289/ehp.7511141.

[16] Lee, H.H, Lee, C.J, Asaoka, K. (2012). Correlation in the mechanical properties of acrylic denture base resins. Dental Materials Journal, vol. 31, no. 1, p. 157-164, Dol:10.4012/ dmj.2011-205.

[17] Scheu-dental (2014). Scheu-dental.com, Iserlohn, from http:// www.scheu-dental.com, accessed on 2014-02-12.
[18] ASTM D638 (2010). Standard Test Method for Tensile Properties of Plastics, ASTM International, West Conshohocken, Dol:10.1520/D0638-10.

[19] ISO 20795-1:2013. Dentistry- Base Polymers- Part 1: Denture Base Polymers. International Organization for Standardization, Geneva.

[20] ASTM D5045 (2014). Standard Test Methods for PlaneStrain Fracture Toughness and Strain Energy Release Rate of Plastic Materials. ASTM International, West Conshohocken, DOI:10.1520/D5045-14.

[21] Sulym, I.Y., Borysenko, M.V., Goncharuk, O.V., Terpilowski, K., Sternik, D., Chibowski, K., Gun'ko, V.M. (2011). Structural and hydrophobic-hydrophilic properties of nanosilica/zirconia alone and with adsorbed PDMS. Applied Surface Science, vol. 258, no. 1, p. 270-277, D0l:10.1016/j.apsusc.2011.08.045.

[22] Lazzara, G., Milioto, S. (2010). Dispersions of nanosilica in biocompatible copolymers. Polymer Degradation and Stability, vol. 95, no. 4, p. 610-617, Dol:10.1016/j. polymdegradstab.2009.12.007.

[23] Zhu, A., Cai, A., Zhou, W., Shi, Z. (2008). Effect of flexibility of grafted polymer on the morphology and property of nanosilica/ PVC composites. Applied Surface Science, vol. 254, no. 13, p. 3745-3752, D0I:10.1016/j.apsusc.2007.11.042.

[24] Balos, S., Sidjanin, L., Pilic, B. (2014). Indentation size effect in autopolymerized and microwave post treated Polymethyl methacrylate denture reline resin. Acta Polytechnical Hungarica, vol. 11, no. 7, p. 239-249.

[25] Lamb, D.J, Ellis, B, Priestley, D. (1983) The effects of process variables on levels of residual monomer in autopolymerizing dental acrylic resin. Journal of Dentistry, vol. 11, no. 1, p. 8088, D0I:10.1016/0300-5712(83)90051-9.

[26] Odian, G. (1991). Principles of Polymerization, 3rd ed., Wiley, New York, p. 24-39.

[27] Van Krevelen D.W., Nijenhuis K.T. (2009). Properties of Polymers: Their Correlation with Chemical Structure; Their Numerical Estimation and Prediction from Additive Group Contributions. 4th ed., Elsevier, Amsterdam, p. 383-500, D0I:10.1016/B978-0-08-054819-7.00013-3.

[28] Landel, R.F, Nielsen, L.E. (1994). Mechanical Properties of Polymers and Composites, $2^{\text {nd }}$ ed., revised and expanded, Marcel Dekker, New York, p. 233-299.

[29] Rosen, C.Z, Hiremath, B.V, Newnham, R.E. (1991). Piezoelectricity: Key Papers in Physics. American Institute of Physics, p. 159-181. 